Check for updates

Cite this: RSC Adv., 2019, 9, 25544

Received 27th June 2019

Accepted 2nd August 2019

DOI: $10.1039 / c 9 r a 04869 c$

rsc.li/rsc-advances

\section{Core-shell architecture based on bio-sourced porous carbon: the shape formation mechanism at the solid/liquid interface layer}

\begin{abstract}
Anfar Zakaria, (D) *abc Jada Amane ${ }^{\mathrm{bc}}$ and El Alem Noureddine ${ }^{\mathrm{a}}$
The overall goal of this work was to activate agri-food wastes by microbial action, which makes it possible to produce bio-digestate and energy (methane). The resulting bio-digestate could be transformed to porous carbon (PC), which was used for the preparation of core-shell particles with alginate (bio-polymer) and a calcium ion layer. Furthermore, surface charge measurements showed electrostatic attractions occurring between the alginate, calcium $\left(\mathrm{Ca}^{2+}\right)$ ions and the $\mathrm{PC}$, hence leading to the formation of core (PC)-shell (alginate-calcium ions) particles. However, in the absence of calcium ions, no electrostatic attractions were observed between the PC and the alginate. In the dried state (using scanning electronic microscopy analysis (SEM)) and in the hydrate state (using numerical microscopy), the designed coreshell architecture was confirmed. Transmission electron microscopy (TEM) shows that the PC particles were graphitic and porous. In addition, both Raman spectroscopy (RS) and X-ray photoelectron spectroscopy (XPS) showed the presence of several chemical functions, in particular hydroxyl $(-\mathrm{O}-\mathrm{H})$ and carboxylic groups $(-\mathrm{COO}-\mathrm{H})$. In aqueous media, the results showed that the PC was negatively charged and its surface charge and particle size were found to be very sensitive to the variation in $\mathrm{pH}$. Finally, the core-shell particles were used as an adsorbent for the removal of methylene blue (MB), crystal violet (CV) and congo red (CR) molecules from wastewater. The overall data indicated efficient dye removal, without the occurrence of the solid/liquid separation problem.
\end{abstract}

\section{Introduction}

Over the last few years, human activities have allowed the increase in toxic industrial effluents, irrespective of their sources. These contaminants result in various diseases and disorders in the ecosystem, ${ }^{\mathbf{1 - 3}}$ as they are easily accumulated in living organisms and dispersed into aquatic systems. As an example, in Morocco, agri-food industries are a major consumer of water and the largest producers of pollution, and this is characterized by their higher COD and microorganism content. ${ }^{4}$ Therefore, it is necessary to remove these contaminants in order to prevent hazardous health effects in human beings. Many techniques including adsorption and anaerobic digestion have been used to degrade these pollutants. ${ }^{\mathbf{5}-18}$ However, these techniques are generally limited when applied separately, requiring coupling and/or hybrid processes. ${ }^{5}$

\footnotetext{
${ }^{a}$ Materials and Environment Laboratory, Ibn Zohr University, Agadir, 8000, Morocco. E-mail: Zakaria.anfar@uha.fr; Tel: +21255530757

${ }^{b}$ Mulhouse Materials Science Institute - CNRS, University Haute Alsace, F-68100, Mulhouse, France

'University of Strasbourg, Strasbourg, F-67081, France

$\dagger$ Electronic supplementary information (ESI) available: Effects of pH, adsorption isotherms, numerical macroscopic images and elemental analysis of the digestate and the PC. See DOI: 10.1039/c9ra04869c
}

To better understand the complexity of agri-food waste treatment based on single techniques, the anaerobic digestion process $(\mathrm{AD})$ was taken as an example. In the $\mathrm{AD}$ process, the degradation of agri-food wastes to bio-methane (75\%) was performed using microorganisms under certain temperature and pressure conditions, and this technique was highly recommended for these types of waste in terms of energy production. ${ }^{4}$ Nevertheless, the resulting bio-digestate remains the big problem of the $\mathrm{AD}$ process. In fact, the production of methane gas from agri-food wastes does not mean that the problem has been solved, but unexpectedly, the bio-product could also be toxic to the environmental media. Recently, researchers around the world have found ways to reduce this problem by converting the digestate into carbonaceous materials (e.g. Biochar, activated carbon and char). ${ }^{19-22}$ Indeed, they considered that the physicochemical properties of the biodigestate could become suitable for the preparation of functional carbonaceous materials after microbial action using the $\mathrm{AD}$ process. Then, these carbonaceous materials were used for environmental remediation (in most cases the carbonaceous materials have been used as adsorbents). ${ }^{23}$ In fact, adsorption using porous materials is crucial for applications relating to the environment due to their large specific surface area and physicochemical properties. $^{24}$ 
The two main problems related to carbonaceous materials produced by digestate are their regeneration and the solid/ liquid phase separation. So, the objective of the present work was to use the raw bio-digestate of agri-food organic waste to produce porous carbon, which was then used as a basic matrix to prepare core-shell particles based on the bio-polymer alginate and $\mathrm{Ca}^{2+}$ ions. These core-shell particles finally allowed both problems relating to material regeneration and phase separation to be solved.

During the preparation and utilization of the prepared core-shell particles, several chemical interactions occurred between several functional groups of the various components (carbon, alginate and $\mathrm{Ca}^{2+}$ ) that are involved. The study of these interactions will be fruitful for a good understanding of the solid/liquid surface reactions, and for elucidating the core-shell mechanism formation as well as the mechanism of the removal of the pollutants from wastewater, especially as very few articles in the literature deal with these interactions in more detail. For these reasons, powerful surface characterizations and interface techniques were used.

The experimental section of the present work began by the preparation of the PC from the bio-digestate derived from agri-food organic waste. Then, the physicochemical, structural and morphological properties of this material were evaluated on two levels: in the hydrated and dried states. After determining these properties, the PC was then used to prepare core-shell particles with the use of alginate and calcium. The procedure used is described and the mechanism of formation of the particles is discussed based on the characterization techniques in the dispersed medium. Finally, the efficiencies of the final particles to eliminate toxic pollutants and to solve the problem of the solid/liquid phase separation have been evaluated and discussed.

\section{Experimental section}

\subsection{Chemical reagents and preparation of aqueous solutions}

The reagents used in this work were: $\mathrm{NaOH}$ (Sigma-Aldrich, >95\%), $\mathrm{HCl}$ (Sigma-Aldrich, >37\%), methylene blue (Sigma-Aldrich, dye content $>82 \%$ ), $\mathrm{H}_{2} \mathrm{SO}_{4}$ (Sigma-Aldrich, 99.99\%), alginate (SigmaAldrich, primary grade), distilled water (laboratory grade), $\mathrm{CaCl}_{2}$ (Sigma-Aldrich, $>99 \%$ ), and cethyltrimethyl ammonium chloride (CTACl) (Sigma-Aldrich, $25 \mathrm{wt} \%$ in $\mathrm{H}_{2} \mathrm{O}$ ). The aqueous dispersions used in this work were prepared and placed in glass vials and kept for potential use. The PC solution $\left(0.12 \mathrm{~g} \mathrm{~L}^{-1}\right)$ was prepared using $6 \mathrm{mg}$ of PC mixed with $50 \mathrm{~mL}$ of distilled water and then ultrasonicated for $10 \mathrm{~min}$. Adjustment of the $\mathrm{pH}$ was performed by adding small amounts of $\mathrm{NaOH}(0.1 \mathrm{M})$ and $\mathrm{HCl}(0.1 \mathrm{M})$ aqueous solutions. The alginate solution $\left(1 \mathrm{~g} \mathrm{~L}^{-1}\right)$ was elaborated using $1 \mathrm{~g}$ of alginate mixed with $1 \mathrm{~L}$ of distilled water and then stirred for $6 \mathrm{~h}$. $\mathrm{CaCl}_{2}(0.1 \mathrm{M})$ and CTACl solutions $\left(6.25 \times 10^{-4} \mathrm{M}\right)$ were prepared from dilution of $1 \mathrm{M}$ stock solutions.

\subsection{Preparation of $\mathbf{P C}$}

The experimental protocol that was followed to prepare the PC can be counted in several stages. Initially, four agri-food organic waste materials were methanized in a mesophilic system at $38 \pm$
$1{ }^{\circ} \mathrm{C}$ for $72 \mathrm{~h}$, followed by 13 days of stabilization. Then, the residue (bio-digestate) was dried at $100{ }^{\circ} \mathrm{C}$ for 24 hours and washed with tap water several times. After this, the filtrate was chemically activated using sulfuric acid, $\mathrm{H}_{2} \mathrm{SO}_{4}(\mathrm{pH}=2)$, with 12 hours of stirring. The final product was filtered, washed with water and ethanol, and finally dried at $100{ }^{\circ} \mathrm{C}$ for 24 hours. In the last step (thermal activation), the filtrate was placed in a furnace at a heating rate of $5{ }^{\circ} \mathrm{C} \mathrm{min}^{-1}$ under nitrogen for $3 \mathrm{~h}$. In the present work, eight treatment temperatures ranging from 200 to $600{ }^{\circ} \mathrm{C}$ were investigated. The optimum temperature was chosen to be at $350{ }^{\circ} \mathrm{C}$. Indeed, in both temperature treatments at 200 and $250{ }^{\circ} \mathrm{C}$, a small amount of leaching of the PC was observed during the adsorption of methylene blue (MB) as a model. For the temperature treatment performed at $300{ }^{\circ} \mathrm{C}$, the prepared material was thermally stable and the removal of MB reached a maximum value of $100 \%$ with an initial concentration of $50 \mathrm{mg} \mathrm{L}^{-1}$ (Fig. 1).

\subsection{Design of the core (PC)-shell (alginate-calcium) particles: PC@alginate}

The core (PC)-shell (alginate-calcium) particles used in this work were prepared as follows: $1 \mathrm{~g}$ of alginate powder was dissolved in $100 \mathrm{~mL}$ of distilled water with 6 hours of stirring, then, $1 \mathrm{~g}$ of PC was added and the mixture was stirred for 2 hours followed by $30 \mathrm{~min}$ of sonication (Sonimasse $150 \mathrm{TS}, 20 \mathrm{kHz}$, sonicating power output of $160 \mathrm{~W}$ ). In addition, a solution of $\mathrm{CaCl}_{2}$ with a known concentration was placed in a crystallizer and kept under low stirring $(30 \mathrm{rpm})$. The preparation of PC@alginate was ensured by mixing both solutions using a pump with a speed of $20 \mathrm{~mL} \mathrm{~h}^{-1}$. Indeed, when each droplet of the PC@alginate solution was brought into contact with the $\mathrm{Ca}^{2+}$ ions, a capsule membrane was instantly formed with the carboxylic groups of the alginate, and the PC was immobilized inside. Finally, the capsules were washed with distilled water and stored in aqueous medium (Fig. 2). The core-shell particles were labelled as PC@alginate.

\subsection{Solid/liquid interface characterization}

The curve representing the surface potential variation as a function of the amount of the cethyltrimethyl ammonium chloride (CTACl) surfactant added, mainly shows the interaction that occurs between the negatively charged PC surface sites

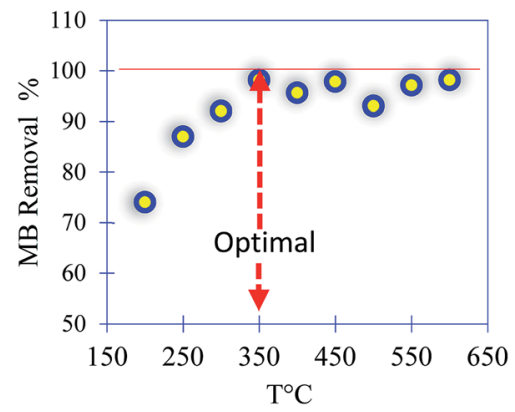

Fig. $1 \mathrm{MB}$ removal efficiency versus the temperature of treatment of the PC. 


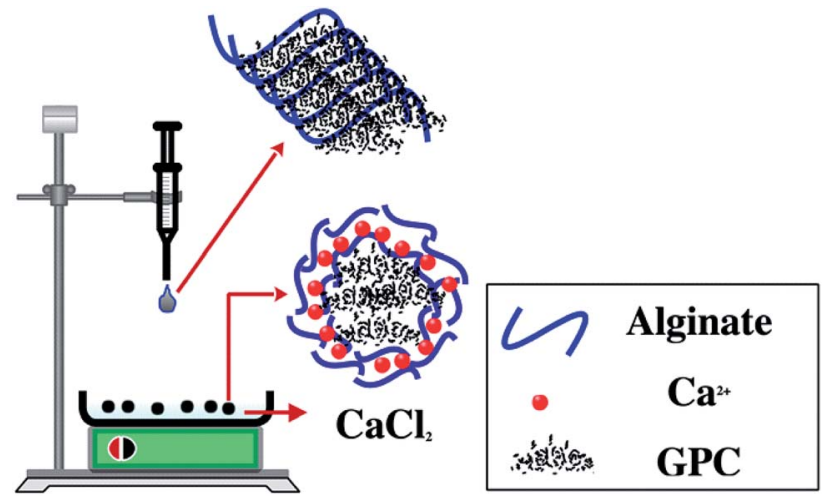

Fig. 2 Experimental protocol for (carbonaceous) core-shell (alginate-calcium ions) particle preparation.

and the positively charged CTACl head groups. The resulting titration curve of the PC by the CTACl surfactant finally reflects the surface electrical properties of the PC. The Müteck PCD 02 apparatus was used for monitoring the titration curve of the PC by the CTACl surfactant. This apparatus allowing the PC surface potential measurements, contained a cylindrical chamber and a piston made of poly(tetrafluoroethylene). ${ }^{25}$ Thus, $10 \mathrm{~mL}$ of the PC aqueous suspension $\left(0.12 \mathrm{~g} \mathrm{~L}^{-1}\right.$, dispersed under ultrasound for $10 \mathrm{~min})$ was first placed in the space $(0.5 \mathrm{~mm})$ between the cylindrical chamber wall and the piston. Thereafter, at each minute, a given amount of the aqueous CTACl solution was added and the potential was measured between the two electrodes placed inside the cylindrical chamber. Since the PCD 02 apparatus allows measurements of relative potential values, to avoid data disparity, the obtained surface potential was then normalized to its maximum magnitude. The measurements of the particle sizes of the PC in aqueous dispersion as a function of $\mathrm{pH}$ variation were performed by Dynamic Light Scattering (DLS), using Coulter Model N4S (Coultronics) apparatus that operates with a $4 \mathrm{~mW}$ helium-neon laser (wavelength $=632.8$ $\mathrm{nm}$ ) and an optical system that detects at a $90^{\circ}$ angle the light scattered by the sample, as described elsewhere. ${ }^{26,27}$ The measurements of the PC zeta potentials were carried out at ambient temperature with a Zetaphoremeter II model Z3000 purchased from SEPHY, as described elsewhere. ${ }^{25}$

\subsection{Characterization techniques in the dried state}

Transmission Electron Microscopy (TEM) analyzes were done using a Philips CM 200, operating at an accelerating voltage of $20-200 \mathrm{kV}$ and with a magnification ranging from $\times 10000$ to $\times 200000$. The PC was analyzed using a scanning electron microscope FEI, Model Quanta 400. The equipment used to perform the various Raman analyzes was a spectrometer Horiba model LabRAM BX40, using a CCD detector, a laser line of $532 \mathrm{~nm}$ and a $100 \times$ objective lens with a laser power of $1.6 \mathrm{~mW}$. Moreover, X-ray Photoelectron Spectroscopy (XPS) was carried out using a Thermo Fisher Scientific ESCALAB 250Xi X-ray photoelectron spectroscopy system equipped with an $\mathrm{Al} \mathrm{Ka} \mathrm{X-}$ ray source $=1486.7 \mathrm{eV}$ to study the surface chemical compositions of the synthesized PC samples. Confocal microscopy (Axio
Imager M2 LSM 700 ordered by the ZEN 2012 software) was used to confirm the designed core-shell adsorbent. X-ray diffraction patterns were collected on a PANalytical MPD X'Pert Pro diffractometer, operating with $\mathrm{Cu} \mathrm{K}_{\alpha}$ radiation $\left(K_{\alpha}=0.15418\right.$ $\mathrm{nm}$ ), equipped with an X'Celerator real-time multiple strip detector (active length $=2.12^{\circ} 2 \theta$ ). The powder patterns were collected at $295 \mathrm{~K}$ in the range $5^{\circ}<2 \theta<90^{\circ}$, with step $=0.017^{\circ}$ $2 \theta$, and time $/ \mathrm{step}=220 \mathrm{~s}$.

\subsection{MB molecule removal experiments}

The removal tests of dyes molecules from aqueous solution using the PC@alginate particles were conducted using a batch system. The effects of $\mathrm{pH}$ on the adsorption of dyes onto PC@alginate were investigated using $40 \mathrm{~mL}\left(10 \mathrm{mg} \mathrm{L}^{-1}\right)$ at different pHs (3-12). The $\mathrm{pH}$ of the solution was adjusted by adding small amounts of $\mathrm{HCl}(0.1 \mathrm{M})$ and $\mathrm{NaOH}(0.1 \mathrm{M})$ aqueous solutions to various PC@alginate dispersions. The effects of the initial dye concentration $\left(5-40 \mathrm{mg} \mathrm{L}^{-1}\right)$ were evaluated using $25 \mathrm{mg}$ of PC@alginate and $40 \mathrm{~mL}$ aqueous solution of the dyes. Finally, the mixture was easily separated using a previously cleaned spatula, and the equilibrium concentration of MB was analyzed by a UV-vis spectrophotometer. The removal efficiency and adsorption capacity at equilibrium were calculated as follows:

$$
\begin{gathered}
\% \text { removal }=\frac{\left(C_{0}-C_{\mathrm{e}}\right)}{C_{0}} \times 100 \\
\% \text { removal }=\left(C_{0}-C_{\mathrm{e}}\right) \times \frac{m}{V}
\end{gathered}
$$

where $C_{0}$ and $C_{\mathrm{e}}$ are the initial and equilibrium concentrations, respectively, of the dyes in $\mathrm{mg} \mathrm{L}^{-1}, m(\mathrm{~g})$ is the amount of adsorbent and $V(\mathrm{~L})$ is the volume of the solution.

In order to investigate the adsorbent reusability, eight cycles of adsorption-desorption were carried out using $25 \mathrm{mg}$ of PC@alginate loaded with dyes, with $20 \mathrm{~mL}$ of $\mathrm{HCl}(0.1 \mathrm{M})$ and $\mathrm{NaOH}(0.1 \mathrm{M})$ with $30 \mathrm{~min}$ of agitation. To fit the isotherm data, Langmuir and Freundlich equations were used (eqn (3) and $(4)) .^{2,28-31}$

$$
\begin{gathered}
\frac{C_{\mathrm{e}}}{Q_{\mathrm{e}}}=\frac{1}{k_{\mathrm{L}} Q_{\max }}+\frac{C_{\mathrm{e}}}{Q_{\max }} \\
\ln \left(Q_{\mathrm{e}}\right)=\frac{1}{n} \ln \left(C_{\mathrm{e}}\right)+\ln \left(k_{\mathrm{F}}\right)
\end{gathered}
$$

where $C_{\mathrm{e}}$ and $Q_{\mathrm{e}}$ are the concentration and amount at equilibrium, $k_{\mathrm{L}}$ is a direct measure of the intensity of the adsorption process, $Q_{\max }$ is the maximum adsorption capacity, $k_{\mathrm{F}}$ is the adsorption capacity, and $n$ reflects the adsorption intensity $(1 / n$ $=0$ irreversible adsorption; $1 / n>1$ unfavorable adsorption, $0<$ $1 / n<1$ favorable adsorption).

\section{Results and discussion}

\subsection{Characterization of prepared material in the dried state}

3.1.1. Scanning electron microscopy (SEM) and transmission electron microscopy (TEM). To acquire the 
morphological characteristics of the digestate and PC material, SEM analysis was performed (Fig. 3). Before treatment, the digestate surface is quite compact and it does not have many pores. When the surface is chemically attacked by sulfuric acid and then heat-treated, a change in the morphological characteristics is observed. After treatment, the morphological properties are modified. Indeed, the surface becomes very smooth and macroporous. The MEB resolution is still not able to permit observation of smaller pores. Therefore, TEM analysis was performed to assess the presence of meso- and micro-pores.

Micrographs of typical areas of PC at $20 \mathrm{~nm}$ are shown in Fig. $4 \mathrm{a}$ and $\mathrm{b}$. As can be observed in these figures, the PC has a disordered microporous structure, and is made up of arranged curved graphene layers. ${ }^{32,33}$ Furthermore, numerous graphene sheets with different dimensions and shapes are clearly observed, that are at $5 \AA$ spacings, which allow the creation of micropores. ${ }^{33,34}$ However, the PC exhibits a much lower packing density of carbon sheets in some regions (more compact structure) and not in others. ${ }^{35}$ Finally, we can see in Fig. 4a and $b$ that the TEM images confirm the amorphous structure of our material, with graphite layers being observed as is already reported in some works. ${ }^{36}$ From Fig. 4c, we can observe the characteristic planes of amorphous carbon around 20-25 $2 \theta$ and the region of $40-452 \theta$ degree. ${ }^{37,38}$ The XRD analysis shows an amorphous phase of the PC adsorbent by the presence of characteristic peaks of graphite (around $262 \theta$ ) and activated carbon, and this confirms the chemical carbonaceous structure of our prepared sample.

3.1.2. Elemental analysis. Elemental analyzes of the digestate, and of the PC, were performed by the EDS technique, as presented in Fig. S1. $\dagger$ These analyzes showed the presence of some impurities such as $\mathrm{Na}, \mathrm{Al}, \mathrm{Si}, \mathrm{S}, \mathrm{K}, \mathrm{Ca}, \mathrm{Fe}, \mathrm{Mg}$ and $\mathrm{Cl}$. The presence of these elements has been explained by the use of some chemical reagents during the process of preparation of the $\mathrm{PC}\left(\mathrm{H}_{2} \mathrm{SO}_{4}\right.$ for example) and/or the origin of raw material (agri-food wastes), which is characterized by heterogeneous chemical composition. The EDS analysis, on the other hand,

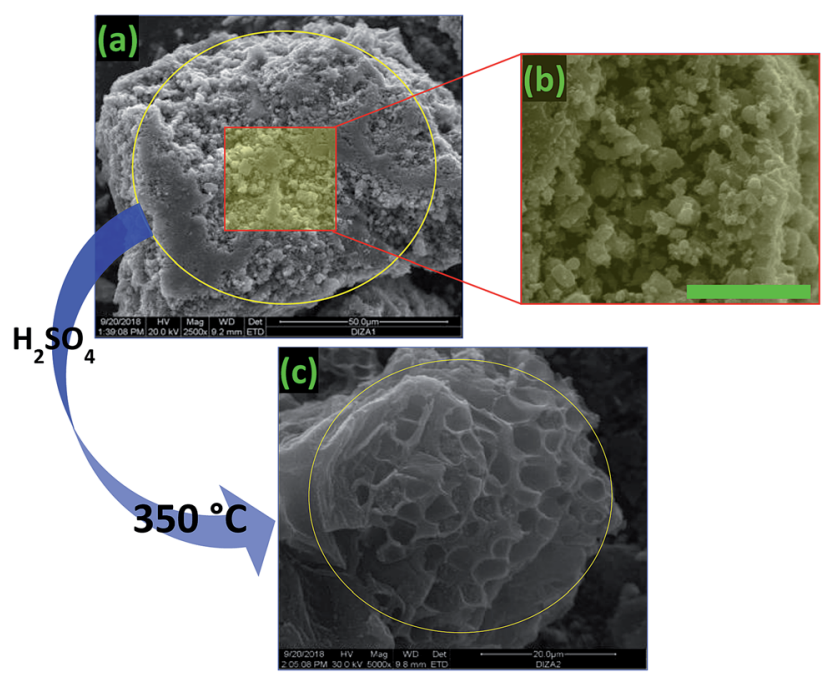

Fig. 3 (a) and (b) SEM images of the raw digestate, and (c) an SEM image of the prepared PC.
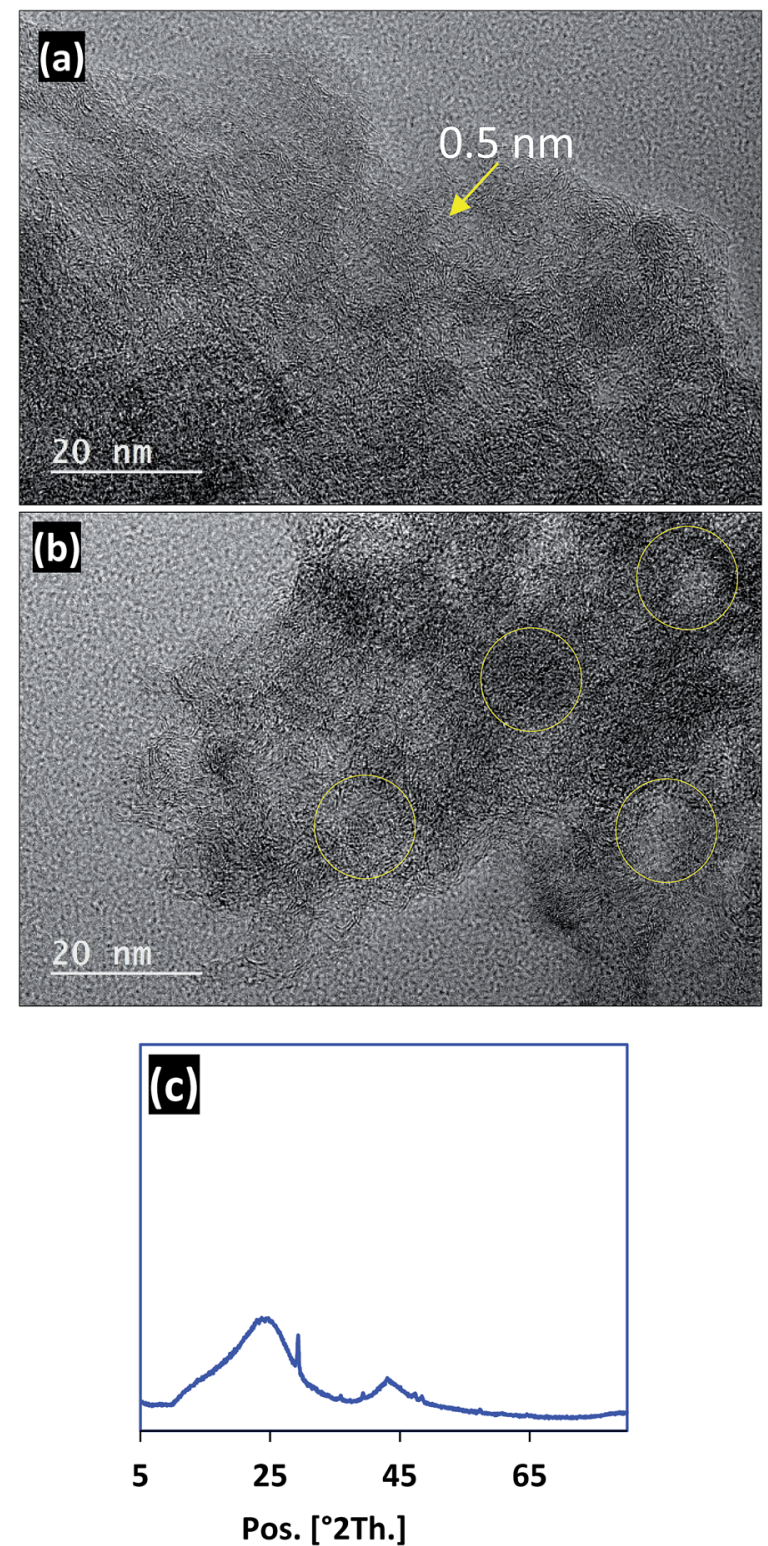

Fig. 4 (a) and (b) TEM images of the prepared PC and (c) the XRD spectrum of the prepared PC.

indicated an increase in the carbon content and a decrease in the oxygen content after chemical and thermal treatments. Table S1 $\uparrow$ shows that the atomic percentage of carbon increased by $45.26 \%$, while a decrease by $30.56 \%$ was observed for the oxygen concentration after the preparation of PC. The present analysis shows that the PC consists mainly of carbon and oxygen, and this is consistent with other techniques.

3.1.3. Functional group characterization. To characterize the oxygen-containing functional groups on the surface of the PC sample, XPS analysis was performed. From Fig. $5 a$ and $b$, the surface of the PC was made up mainly of $\mathrm{sp}^{2}$-bonded carbon, and $\mathrm{C}-\mathrm{OH}$ and $\mathrm{C}=\mathrm{O}$ bonds. The $\mathrm{sp}^{2}$-bonded carbon atoms were detected at $284.99 \mathrm{eV}, \mathrm{C}-\mathrm{OH}$ broad peaks were confirmed at $286.2 \mathrm{eV}$ and $\mathrm{C}=\mathrm{O}$ bonds were observed at $288.45 \mathrm{eV}^{2,29,39}$ The deconvolution of the O1s band shows three crests at 530,532 
and $533 \mathrm{eV}$, which can be attributed to the $\mathrm{O}$ atoms in phenolic and ether compounds, the carbonyl oxygen atom in anhydrides and lactones, and the oxygen atom in carboxylic acid groups, respectively. ${ }^{\mathbf{4 0 , 4 1}}$ Nevertheless, impurities were detected in the PC structure related to the starting biomass and the reagents used for the preparation of the PC.

As a tool to investigate the functionalization and graphitization of the surface of the PC, Raman analysis was used (Fig. 5d). The results showed that the PC sample presents two broad bands at 1355.22 and $1604.89 \mathrm{~cm}^{-1}$, noted D (disorders) and $\mathrm{G}$ (graphitic), respectively. ${ }^{2}$ The $\mathrm{G}$ band is related to the stretching vibrations of $\mathrm{sp}^{2}$ carbon atoms in the long carbon chains in graphite or the carbon ring. The D band, however, is assigned to the defection of the crystalline structure and disorder arrangement, which gives low symmetry and defects. ${ }^{42,43}$ In addition, the relative intensity between $I_{\mathrm{G}} / I_{\mathrm{D}}$ was used to calculate the average crystallite size " $L_{\mathrm{a}}$ ", which shows the structural disorder degree and hence informs us about the size of the graphitic domains of the prepared PC. ${ }^{\mathbf{4 4 5}}$ The same results have been found in reported works aimed at the preparation of carbon materials. ${ }^{46,47}$

\subsection{Characterization of prepared material in the hydrate} state

3.2.1. Surface charge measurements of $P C$ particles. The surface charge of the $\mathrm{PC}$ was studied as a function of $\mathrm{pH}$ (Fig. 6) using cethyltrimethyl ammonium chloride (CTACl) as a titrant. After $\mathrm{pH}$ adjustment using small amounts of $\mathrm{HCl}(0.1 \mathrm{M})$ and $\mathrm{NaOH}(0.1 \mathrm{M})$ aqueous solutions, $10 \mathrm{~mL}$ of the PC suspension $\left(0.12 \mathrm{~g} \mathrm{~L}^{-1}\right)$ was placed $0.5 \mathrm{~mm}$ between the cylinder and the
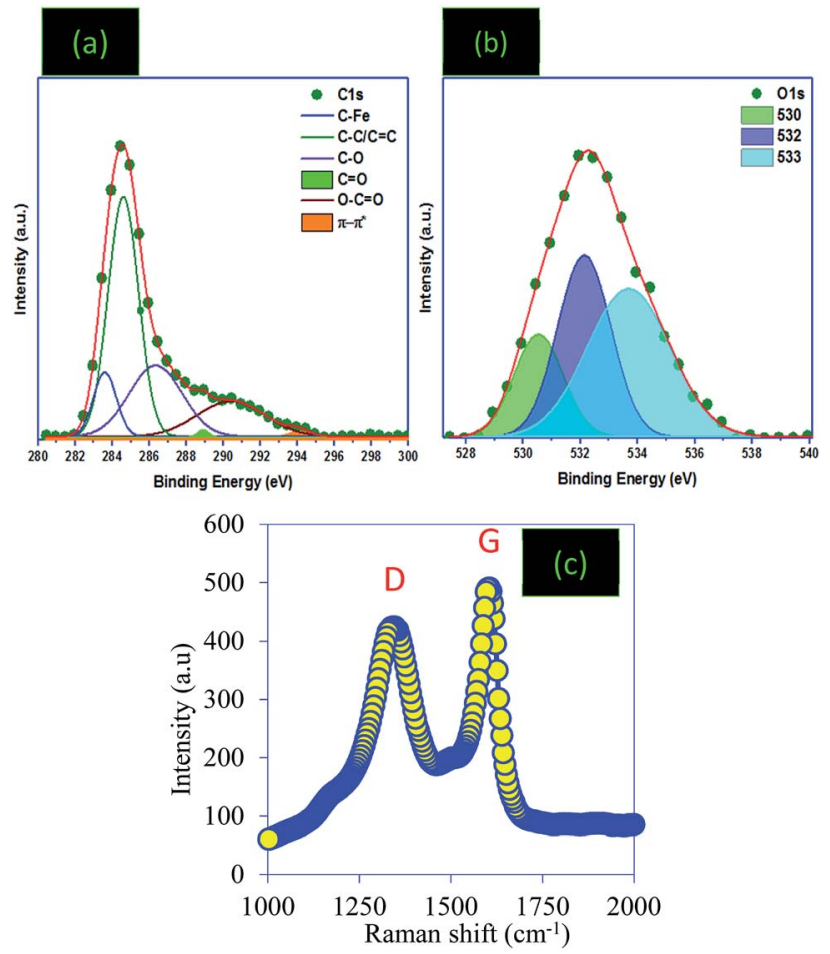

Fig. 5 (a) and (b) XPS and (c) Raman analysis of the PC material. piston. Before analysis, the solutions were dispersed under ultrasound for 10 minutes. The titration was carried out by the addition of variable amounts of aqueous solution of CTACl (6.25 $\left.\times 10^{-6} \mathrm{M}\right)$ at determined periods using a micropipette. At the natural $\mathrm{pH}(\mathrm{pH}=8.3)$, the potential was initially negative, which reflects the fact that the PC particles are negatively charged due to the ionization of the $-\mathrm{COOH}$ and $-\mathrm{OH}$ groups present on the surface (already confirmed by XPS and Raman analyzes) (Fig. 5). When the $\mathrm{pH}>6.5$, and after addition of $\mathrm{CTACl}$, the negative charges of the PC particles are progressively compensated by $\mathrm{CTA}^{+}$ions to the point where the particles become neutralized ( $\mathrm{SIP}=0 \mathrm{mV}$ ) (Fig. 6a). The number of moles of CTACl that made it possible to reach the zero charges correspond to the equivalent point. Therefore, the values of the equivalent points increase as the $\mathrm{pH}$ increases $\left(10^{-7} \mathrm{meq} \cdot \mathrm{g}^{-1}\right.$ for $\mathrm{pH}=6.2,1.75 \times 10^{-7} \mathrm{meq} . \mathrm{g}^{-1}$ for $\mathrm{pH}=8.32,2.25 \times 10^{-7}$ meq. $\mathrm{g}^{-1}$ for $\mathrm{pH}=9.13$ and $2.75 \times 10^{-7} \mathrm{meq} \cdot \mathrm{g}^{-1}$ for $\mathrm{pH}=$ 10.07). Beyond the equivalent points, the excess of cationic surfactant reverses the charge of the PC particles and the surface potential becomes positive. As the surface of the PC is rich in carboxylic and hydroxyl groups, the variation in $\mathrm{pH}$
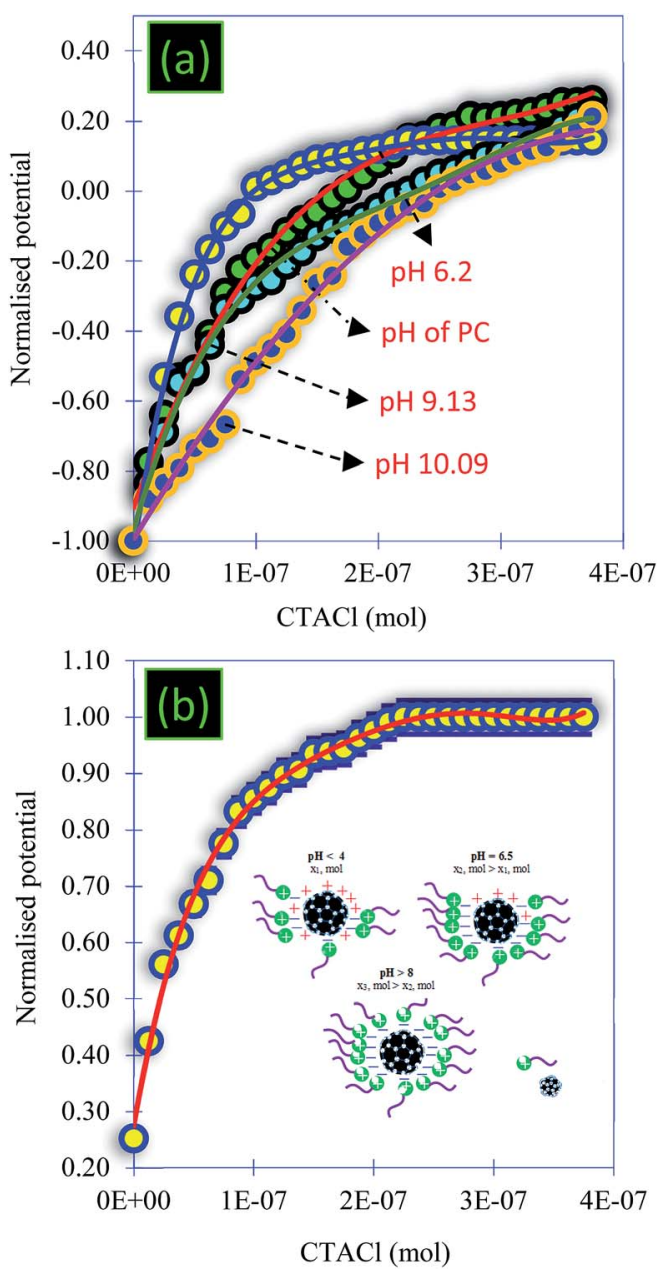

Fig. 6 (a) Titration of the PC solution at different pHs using $\mathrm{CTACl}$ $\left(6.25 \times 10^{-4} \mathrm{M}\right)$ and $(\mathrm{b})$ titration of the $\mathrm{PC}$ solution at acidic $\mathrm{pH}$ using CTACl $\left(6.25 \times 10^{-4} \mathrm{M}\right)$. 
modifies the charge of these groups and makes the surface very polarizable, which favors more electrostatic attraction with $\mathrm{CTA}^{+}$cationic molecules. At $\mathrm{pH}<4$, the measured values indicate a positive charge due to the number of $\mathrm{H}^{+}$ions added (the potential starting point is $+50 \mathrm{mV}$ ) (Fig. $6 \mathrm{~b}$ ). After the addition of the $\mathrm{CTA}^{+}$molecules, no reverse charge was observed. This analysis shows that the PC sample contains negative surface charges that are very sensitive to the aqueous phase $\mathrm{pH}$ changes.

3.2.2. Effect of $\mathbf{p H}$ and temperature on the size and zeta potential of the PC particles. Fig. 7 shows the variation in the size of the PC particles in aqueous medium as a function of $\mathrm{pH}$. The $\mathrm{pH}$ was varied between 3 and 10 to evaluate the particle size. At $\mathrm{pH}=3.4$, the particle diameter of the $\mathrm{PC}$ was found to be $433 \mathrm{~nm}$, and when the $\mathrm{pH}$ changed from 3.4 to 6.1, the size of the PC particles decreased from $433 \mathrm{~nm}$ to $336 \mathrm{~nm}$. The size variation in the $\mathrm{PC}$ at these $\mathrm{pH}$ values can be explained by the decrease in the attraction forces as the $\mathrm{pH}$ increases (Fig. $6 \mathrm{~b}$ confirms the presence of negatively charged particles on the surface, even when the $\mathrm{pH}$ was $<4$ ). In the range of $\mathrm{pH} 7$ to 8 , an increase in the diameter of the PC particles by $78 \mathrm{~nm}$ was observed, which can be explained by the electrical instability in this $\mathrm{pH}$ zone ( $\mathrm{pH}$ near the PZC). At $\mathrm{pH}>8$, the surface becomes negative and the particle size decreased again to $307 \mathrm{~nm}$. In fact, at these $\mathrm{pH}$ values, the carboxylic and phenolic groups were negatively charged, which leads to repulsive electrical forces occurring between the PC particles and hence avoidance of their agglomeration. This analysis is evidence that the particle size in dispersed media is dependent on the aqueous phase $\mathrm{pH}$, as well as evidence for the particles having smaller sizes in the liquid phase compared to those observed by SEM in the dry state.

Note that the PZC is an important parameter for characterizing the $\mathrm{pH}$ of a solid surface and ensuring colloidal stability. ${ }^{\mathbf{4 8 , 4 9}}$ By definition, the PZC refers to the $\mathrm{pH}$ value at which the magnitude of the negative and the positive surface charges are equal. In this work, the surface charge of the PC was characterized using zeta-potential measurements as a function of $\mathrm{pH}$ in the range of $\mathrm{pH}$ 3-11 (Fig. 7b). As shown in Fig. 7b, the isoelectric points were located at $\mathrm{pH} 6.9$, indicating that the surface charge of the PC has a positively charged surface below this value, while it has a negatively charged surface above it. The PC carbon powder showed positive zeta-potential values below about $\mathrm{pH} 3$, indicating the coexistence of positively charged groups at the surface of the particles with less negatively charged oxygen groups $(-\mathrm{COOH}$ and $-\mathrm{OH})$, and this coincides with other work. ${ }^{50,51}$ As we have already shown by surface charge detector measurements, the PZC confirmed that the surface of $\mathrm{PC}$ at the natural $\mathrm{pH}$ was negatively charged due to the introduction of oxygen-containing functional groups. We note that the variation in the electrical surface potential of the PC particles as a function of $\mathrm{pH}$ can be useful for the control of the desorption and the regeneration of PC. ${ }^{48}$

The variation in the size of the particles with the temperature was studied and the temperature control was provided by a thermocouple immersed in the measuring cell (Fig. 7c). The

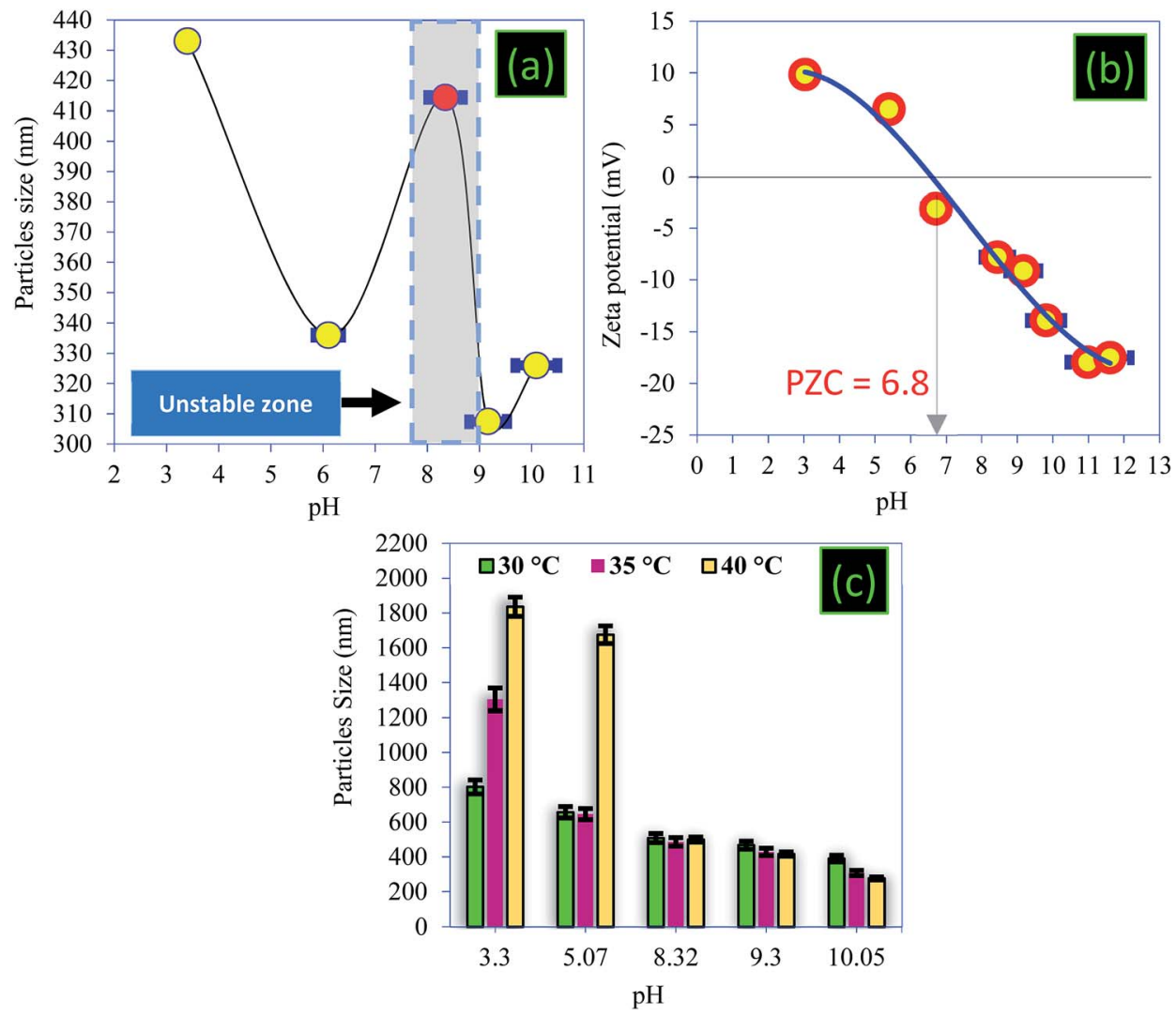

Fig. 7 (a) Particle mean size as a function of $\mathrm{pH}$, (b) zeta potential of the $\mathrm{PC}$, and (c) particle mean size as a function of temperature. 
influence of temperature on the particle size of PC can be summarized in two main points:

- When the $\mathrm{pH}<\mathrm{PZC}$, an increase in temperature favors an increase in particle size, and this increase is very high where the $\mathrm{pH}<3$.

- When the $\mathrm{pH}>\mathrm{PZC}$, an increase in temperature favors a decrease in particle size up to a value equal to $276 \mathrm{~nm}$, recorded at $40{ }^{\circ} \mathrm{C}$.

The peak observed at $20{ }^{\circ} \mathrm{C}$ (Fig. 7a) gradually disappears when the temperature increases. Indeed, the sizes become larger in acidic medium, which prevents the influence of this unstable zone on the particle size. These results show that the highest yields of removal of BM and CV dyes will be recorded at alkaline $\mathrm{pH}$ and at higher temperatures, which is not the case in acidic conditions. As a result, the particle size decreases, resulting in an increase of the surface area of the PC.

\subsection{Chemical mechanism of the formation of the core-shell particles}

Despite the high performance of PC to remove pollutants (due to a developed porous structure and the presence of surface functions), the problem of separation of both liquid and solid phases is still apparent. To solve this problem, PC has been used as a matrix for preparing core-shell particles that are used to remove toxic dyes from aqueous solutions. Before running the adsorption experiments using core-shell particles, the formation process of these particles was investigated using the measurements of the surface charges (Fig. 8 and 9). Thus, the chemical mechanism of core-shell particle formation has been studied following successive titrations:

- Titration 1 (Fig. 8a): titration of alginate solution $\left(1 \mathrm{~g} \mathrm{~L}^{-1}\right)$ with $\mathrm{CaCl}_{2}(0.1 \mathrm{M})$. This titration showed a strong electrostatic interaction occurring between the $\mathrm{Ca}^{2+}$ ions and the carboxylic groups of the alginate. Indeed, the reaction at the beginning started with a potential equal to $-510 \mathrm{mV}$ and, after the addition of $6 \times 10^{-7} \mathrm{~mol}$ of $\mathrm{Ca}^{2+}$, the surface potential decreased to $0 \mathrm{mV}$ (Fig. 8a and 9).

- Titration 2 (Fig. 8a): titration of the PC solution $\left(0.12 \mathrm{~g} \mathrm{~L}^{-1}\right)$

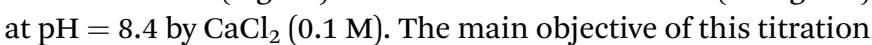
was to verify that the surface of the PC reacts weakly with the $\mathrm{Ca}^{2+}$ molecules. The analysis of Fig. 8a shows a weak interaction occurring between the $\mathrm{PC}$ and the $\mathrm{Ca}^{2+}$ ions after the addition of the same amount of $\mathrm{CaCl}_{2}$ as in titration 1. The comparison between titrations 1 and 2 (Fig. 8a) allowed an exponential curve to be seen in the case of alginate $/ \mathrm{Ca}^{2+}$ and the opposite for the $\mathrm{PC} / \mathrm{Ca}^{2+}$ system. Indeed, in both cases we started with a normalized potential (ISP) equal to -1 and after the addition of $6 \times 10^{-7} \mathrm{~mol}$ of $\mathrm{Ca}^{2+}$, the saturation plateau (ISP $=0 \mathrm{mV}$ ) was detected in the case of the alginate $/ \mathrm{Ca}^{2+}$ system, whilst in the $\mathrm{PC} / \mathrm{Ca}^{2+}$ system, a plateau of the ISP around $0.9 \mathrm{mV}$ was reached following the addition of large amounts of $\mathrm{CaCl}_{2}$.

- Titration 3 (Fig. 8b): titration of the PC solution $\left(0.12 \mathrm{~g} \mathrm{~L}^{-1}\right)$ at $\mathrm{pH}=8.4$ with alginate $\left(1 \mathrm{~g} \mathrm{~L}^{-1}\right)$. This experiment showed that the surface of the PC does not interact with that of alginate. At the beginning of the reaction, the surface of the PC indicates a negative potential equal to $-156 \mathrm{mV}$, which remains constant
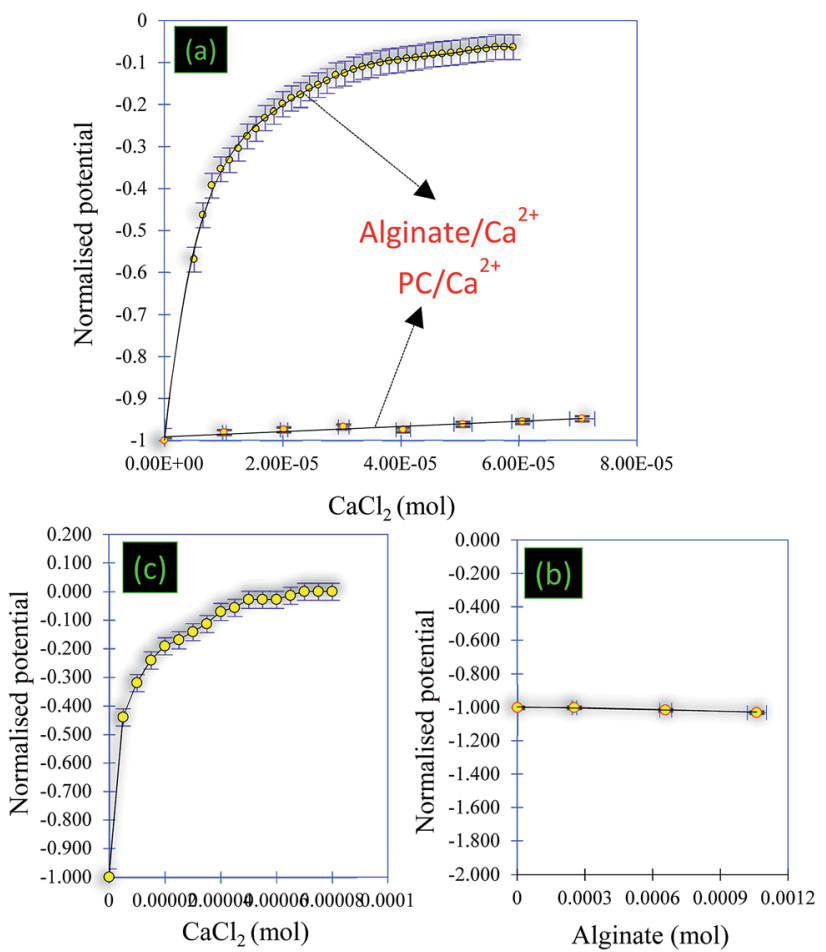

Fig. 8 (a) Titration of the $\mathrm{PC}$ solution $\left(0.12 \mathrm{~g} \mathrm{~L}^{-1}\right)$ using $\mathrm{CaCl}_{2}(0.1 \mathrm{M})$ and titration of the alginate solution $\left(1 \mathrm{~g} \mathrm{~L}^{-1}\right)$ using $\mathrm{CaCl}_{2}(0.1 \mathrm{M})$. (b) Titration of the PC solution $(\mathrm{pH}=8.4)\left(0.12 \mathrm{~g} \mathrm{~L}^{-1}\right)$ using alginate $(1 \mathrm{~g}$ $\mathrm{L}^{-1}$ ) and (c) titration of the PC(aalginate mixture using $\mathrm{CaCl}_{2}(0.1 \mathrm{M})$.

after the addition of the alginate molecules (Fig. 8b and 9). The repulsive forces between the two negatively charged surfaces explained these results. Fig. 8b confirms these results and shows a linear form of the ISP variation as a function of the amount of alginate added.

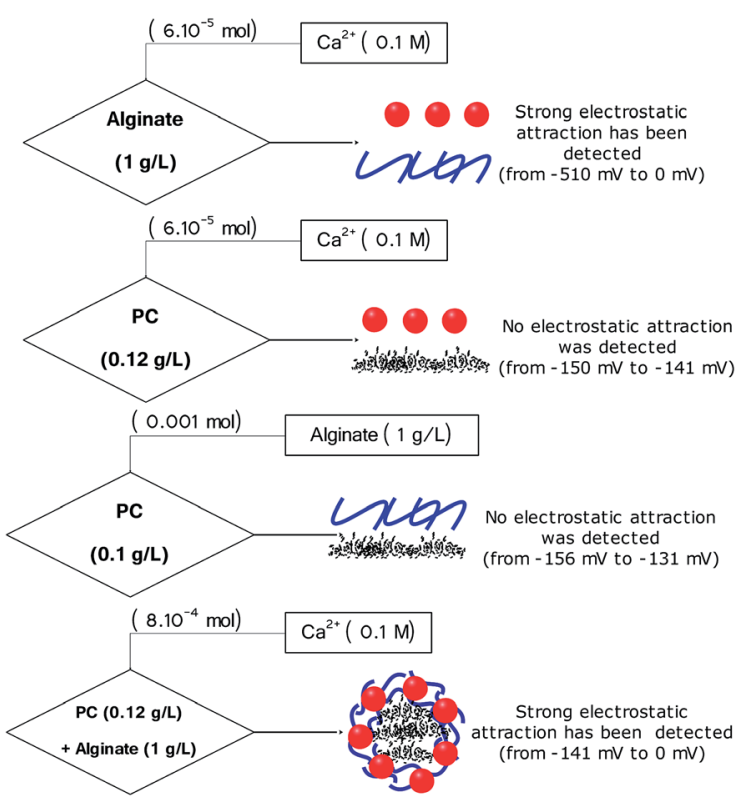

Fig. 9 Chemical mechanism of core-shell particle formation. 
- Titration 4 (Fig. 8c): titration of a mixed solution of PC $\left(0.12 \mathrm{~g} \mathrm{~L}^{-1}\right)$ and alginate $\left(1 \mathrm{~g} \mathrm{~L}^{-1}\right)$ with $\mathrm{CaCl}_{2}(0.1 \mathrm{M})$. Fig. $8 \mathrm{c}$ shows a strong electrostatic interaction (probably between $\mathrm{Ca}^{2+}$ and alginate) and the surface charge saturation is held after the addition of $8 \times 10^{-5} \mathrm{~mol} \mathrm{CaCl}_{2}(0.1 \mathrm{M})$.

In addition, Fig. 9 shows the performed titrations used in this work to describe the mechanism of core-shell particle formation. As a conclusion, the surface charge measurements showed electrostatic attraction and/or repulsion forces occurring between the alginate ions, the calcium ions $\left(\mathrm{Ca}^{2+}\right)$ and the PC, thus leading to the formation of core(carbon)-shell (alginate-calcium ions) particles. However, in the absence of calcium ions, no electrostatic attraction was observed between the PC and the alginate. In addition, the form of the core-shell particles was confirmed by numerical microscopy and the dimensions have been calculated (Fig. S2†).

\subsection{PC surface charge interaction with $M B, C V$ and $C R$}

PC surface charge interactions with different dyes were investigated and CTACl was used as a reference. From Fig. 10, we can conclude that the CR molecule was weakly interfaced with PC compared with $\mathrm{MB}$ and $\mathrm{CV}$. The number of moles of $\mathrm{CR}$ necessary to saturate the surface of the PC was equal $2.5 \times$ $10^{-10} \mathrm{~mol}$ and, in the case of $\mathrm{MB}$ and $\mathrm{CV}$, this value was higher by 60 and 100 times, respectively. These results can be explained by the characteristic surface of PC, which is more sensitive to cationic dyes than to anionic dyes. In addition, this analysis showed that the $\mathrm{CV}$ dye was adsorbed more than the MB dye on the surface of the PC by 0.6 times. This difference in the number of moles can be explained by the tail of the MB molecule, as well as the functional groups of $\mathrm{CV}$, which can be more attractive with the $-\mathrm{COO}-\mathrm{H}$ and $-\mathrm{OH}$ groups of $\mathrm{PC}$, especially with the $\mathrm{N}-\mathrm{H}$ and $\mathrm{SO}_{3}{ }^{-}$groups. This analysis allows the characteristic interactions between the molecules and the surface of the PC to be seen. These results, and those of the characterizations, confirm that the mechanism of adsorption refers to the formation of hydrogen bonding and the electrostatic attraction of the dyes with $\mathrm{C}-\mathrm{O}$ groups. In addition, the fixation of the

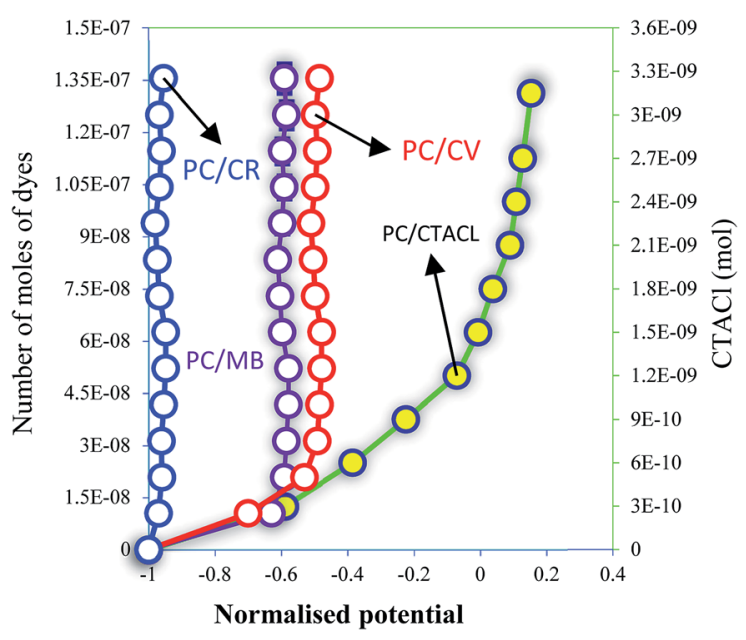

Fig. 10 PC surface charge interactions with $M B, C V$ and $C R$. pollutant molecule inside the adsorbent pores of PC plays a very important role in the dye adsorption mechanism., ${ }^{2,52-54}$

\subsection{Adsorption studies}

The effect of $\mathrm{pH}$ on the MB solution was carried out under the following conditions: $25 \mathrm{mg}$ of adsorbent mass, a contact time of adsorbent-adsorbate of $100 \mathrm{~min}, 40 \mathrm{~mL}$ of dye solutions, and an initial dye concentration of $10 \mathrm{mg} \mathrm{L}^{-1}$ at room temperature.

Fig. S3a $\uparrow$ shows the curve of the removal efficiency measured at different pHs. It can be seen that the $\mathrm{pH}$ of the solution has a critical impact on dye removal. Therefore, when the $\mathrm{pH}$ of the solution was very acidic, the removal of $\mathrm{MB}$ and $\mathrm{CV}$ was very low, whereas it was the opposite when the $\mathrm{pH}$ of the cationic dye solution was higher than 8 . In fact, the availability of negative active sites in PC and the high surface area at this range of $\mathrm{pH}$ explained the higher adsorption capacity of these dyes compared to that of CR.

These results are in agreement with those cited in the above sections and are summarized as the following:

- From Fig. 7a, we demonstrated that the carboxylic and phenolic groups were charged negatively, which leads to a repulsion of the electrical forces between PC particles and avoids agglomeration, which allowed the recording of the lowest values of PC particle sizes $(307 \mathrm{~nm})$.

- From Fig. 6a, the titration of the PC solution at different pHs using CTACl $\left(6.25 \times 10^{-4} \mathrm{M}\right)$ showed that the values of the equivalent point increase as the $\mathrm{pH}$ increases. Therefore, a high amount of carboxylic and hydroxyl functionalization groups characterized the surface of the PC and a variation in the $\mathrm{pH}$ allowed the modification of the charge of these groups, which favored more electrostatic attractions with $\mathrm{MB}$ and $\mathrm{CV}$.

- From Fig. $7 \mathrm{~b}$, in alkaline $\mathrm{pH}\left(\mathrm{pH}>\mathrm{pH}_{\mathrm{PZC}}\right)$, the surface of the PC@alginate was negatively charged, which is in favor of the electrostatic attraction forces that occur between the PC and the cationic dyes. ${ }^{55}$

The adsorption isotherms of MB, CV and CR onto PC@alginate have been calculated using both Langmuir and Freundlich models. ${ }^{56-60}$ The overall data indicate efficient dye removal in the case of $\mathrm{MB}$ and $\mathrm{CV}(>96 \%)$, without the occurrence of the solid/liquid separation problem. As a result of the adsorption isotherms (Fig. S3b $\dagger$ and Table 1), the correlation coefficients showed a good fit in the case of the Langmuir model and the values of $R_{\mathrm{L}}$ showed a favorable adsorption, indicating the achievement of a homogeneously adsorbed monolayer of MB, CV and CR onto PC@alginate.

The reusability and the recovery ability of the adsorbents were considered as crucial economic factors when assessing the cost-effectiveness of the treatment process. ${ }^{61,62}$ The results of regeneration revealed that the core-shell particles showed high reusability efficiencies. Indeed, the regeneration test successfully eluted $91.28 \%$ (for $\mathrm{MB}$ ) and $92.74 \%$ (for $\mathrm{CV}$ ) of the dyes loaded onto PC@alginate after 5 cycles of sorption-desorption (Fig. 11a). In the case of CR, the reusability efficiencies decreased by 5.93 after 5 cycles using $\mathrm{NaOH}(0.1 \mathrm{M})$ (Fig. 11a). In all case systems (MB, CV and CR adsorption), a total recovery of the adsorbent particles was observed (Fig. 11b). 
Table 1 Characteristic kinetic adsorption parameters of MB, CV and $\mathrm{CR}$ adsorption

\begin{tabular}{|c|c|c|c|c|}
\hline \multirow[b]{2}{*}{ Dye } & \multicolumn{4}{|l|}{ Langmuir } \\
\hline & $Q_{\max }\left(\mathrm{mg} \mathrm{g}^{-1}\right)$ & $k_{\mathrm{L}}\left(\mathrm{L} \mathrm{mg}^{-1}\right)$ & $R^{2}$ & $R_{\mathrm{L}}$ \\
\hline MB & 25.906 & 1.550 & 0.9978 & $0.11-0.01$ \\
\hline $\mathrm{CV}$ & 30.959 & 1.318 & 0.9930 & $0.13-0.01$ \\
\hline $\mathrm{CR}$ & 9.0334 & 0.422 & 0.9888 & $0.32-0.05$ \\
\hline
\end{tabular}

\begin{tabular}{lllll}
\hline & Freundlich & & & \\
\cline { 2 - 5 } Dye & $k_{\mathrm{F}}\left(\mathrm{mg}^{1-n} \mathrm{~L}^{n} \mathrm{~g}^{-1}\right)$ & $n$ & $R^{2}$ & $k_{\mathrm{F}}\left(\mathrm{mg}^{1-n} \mathrm{~L}^{n} \mathrm{~g}^{-1}\right)$ \\
\hline MB & 8.545 & 2.758 & 0.3613 & 8.545 \\
$\mathrm{CV}$ & 7.252 & 1.910 & 0.4299 & 7.252 \\
$\mathrm{CR}$ & 1.549 & 1.822 & 0.8858 & 1.549
\end{tabular}
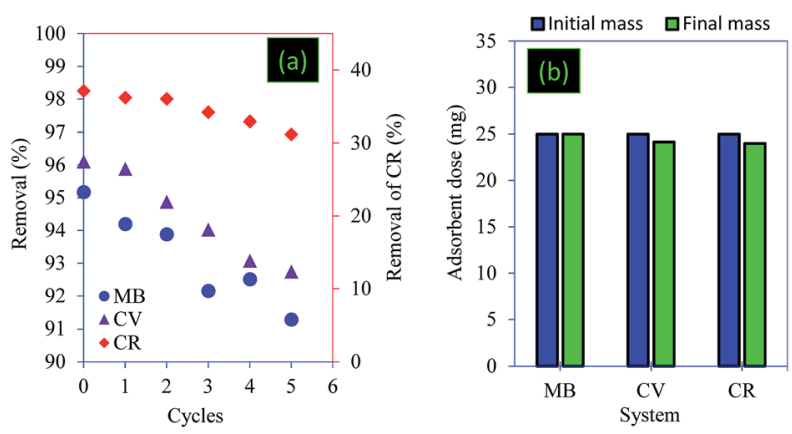

Fig. 11 (a) Reusability and (b) recovery ability of the PC@alginate particles.

\section{Conclusions}

In this work, agri-food organic waste has been transformed into core-shell particles. These particles allow for the elimination of toxic dyes as well as solve the problem relating to the separation of liquid and solid phases after the adsorption process. The main results of the work are:

- The bio-digestate has been transformed into PC with a large specific surface area.

- The characterization of PC shows the structure of activated carbon with the presence of carboxylic and hydroxyl groups.

- In a dispersed medium, the PC sample was very sensitive to the variation in $\mathrm{pH}$. Indeed, the $\mathrm{pH}$ variation makes it possible to reduce the particle size and to increase the electrostatic attraction with the PC. These results were confirmed using characterization techniques in aqueous medium and the surfactant molecule CTACl as a probe. The particle size of PC was very sensitive to temperature variation and the sizes are very small when the medium becomes basic at higher temperatures.

- The mechanism of formation of the core-shell is well evidenced using several titrations and the final form is observed by two-level 2D and 3D analysis using numerical microscopy.

- Core-shell particles were used to remove toxic dyes. Experimental results showed that cationic dyes are more absorbed than anionic ones. According to the Langmuir model, the adsorption capacities were: $25.90 \mathrm{mg} \mathrm{g}^{-1}$ (for MB), $30.95 \mathrm{mg}$ $\mathrm{g}^{-1}$ (for CV) and $9.03 \mathrm{mg} \mathrm{g}^{-1}$ (for CR).

- Core-shell particles are easy to regenerate. The results showed a decrease of 3.89, 3.31, and $5.93 \%$ for MB, CV and CR, respectively.

- The core-shell particles are easy to recover. The results showed that the adsorbent mass loss after adsorption does not exceed $3 \%$.

\section{Conflicts of interest}

The authors declare that they have no conflicts of interest.

\section{Author contributions}

All authors have given approval to the final version of the manuscript.

\section{Acknowledgements}

This work was supported by the framework of the FrancoMoroccan cooperation, research project CEDocs 2018. We thank the Mascir Foundation for their support. We thank FIOUX Philippe (IS2M-Mulhouse-France) for XPS analyses. We thank VIDAL Loïc (IS2M-Mulhouse-France) and KNOPF Stéphan (IS2MMulhouse-France) for SEM and TEM analyses, respectively.

\section{Notes and references}

$1 \mathrm{M}$. Alimohammady, M. Jahangiri, F. Kiani and H. Tahermansouri, New J. Chem., 2017, 41, 8905-8919.

2 M. Zbair, Z. Anfar, H. A. Ahsaine, N. El Alem and M. Ezahri, J. Environ. Manage., 2018, 206, 383-397.

3 M. Zbair, H. Ait Ahsaine and Z. Anfar, J. Cleaner Prod., 2018, 202, 571-581.

4 S. Lhanafi, Z. Anfar, B. Chebli, M. Benafqir, R. El Haouti, Y. Azougarh, M. Abbaz and N. El Alem, Sustainable Environ. Res., 2018, 28, 389-395.

5 Y. Ozay, E. K. Ünşar, Z. Işık, F. Yılmaz, N. Dizge, N. A. Perendeci, M. A. Mazmanci and M. Yalvac, J. Cleaner Prod., 2018, 196, 42-50.

6 R. Su, Q. Li, Y. Chen, B. Gao, Q. Yue and W. Zhou, J. Cleaner Prod., 2019, 209, 20-29.

7 S. Liu, X. Chen, W. Ai and C. Wei, J. Cleaner Prod., 2019, 212, 1062-1071.

8 S. Wong, H. H. Tumari, N. Ngadi, N. B. Mohamed, O. Hassan, R. Mat and N. A. Saidina Amin, J. Cleaner Prod., 2019, 206, 394-406.

9 E. Serrano León, J. A. Perales Vargas-Machuca, E. Lara Corona, Z. Arbib, F. Rogalla and M. Fernández Boizán, $J$. Cleaner Prod., 2018, 198, 931-939.

10 R. M. Novais, A. P. F. Caetano, M. P. Seabra, J. A. Labrincha and R. C. Pullar, J. Cleaner Prod., 2018, 197, 1137-1147.

11 T. L. da Silva, A. C. da Silva, M. G. A. Vieira, M. L. Gimenes and M. G. C. da Silva, J. Cleaner Prod., 2016, 137, 14701478. 
12 O. Kuczman, M. V. D. Gueri, S. N. M. De Souza, W. N. Schirmer, H. J. Alves, D. Secco, W. G. Buratto, C. B. Ribeiro and F. B. Hernandes, J. Cleaner Prod., 2018, 196, 382-389.

13 A. Kumar and H. M. Jena, J. Cleaner Prod., 2016, 137, 12461259.

14 R. Bedoić, L. Čuček, B. Ćosić, D. Krajnc, G. Smoljanić, Z. Kravanja, D. Ljubas, T. Pukšec and N. Duić, J. Cleaner Prod., 2019, 213, 700-709.

15 M. Moretti, M. Van Dael, R. Malina and S. Van Passel, J. Cleaner Prod., 2018, 171, 954-961.

16 A. Pfluger, J. Coontz, V. Zhiteneva, T. Gulliver, L. Cherry, L. Cavanaugh and L. Figueroa, J. Cleaner Prod., 2019, 206, 97-107.

17 A. Ahmad, A. H. Bhat and A. Buang, J. Cleaner Prod., 2018, 171, 1361-1375.

18 R. Kamaraj and S. Vasudevan, New J. Chem., 2016, 40, 22492258.

19 M. Inyang, B. Gao, Y. Yao, Y. Xue, A. R. Zimmerman, P. Pullammanappallil and X. Cao, Bioresour. Technol., 2012, 110, 50-56.

20 M. Inyang, B. Gao, A. Zimmerman, M. Zhang and H. Chen, Chem. Eng. J., 2014, 236, 39-46.

21 Y. Yao, B. Gao, M. Inyang, A. R. Zimmerman, X. Cao, P. Pullammanappallil and L. Yang, Bioresour. Technol., 2011, 102, 6273-6278.

22 M. Inyang, B. Gao, W. Ding, P. Pullammanappallil, A. R. Zimmerman and X. Cao, Sep. Sci. Technol., 2011, 46, 1950-1956.

23 M. Inyang, B. Gao, P. Pullammanappallil, W. Ding and A. R. Zimmerman, Bioresour. Technol., 2010, 101, 8868-8872.

24 B. Coasne, New J. Chem., 2016, 40, 4078-4094.

25 A. Jada, H. Debih and M. Khodja, J. Pet. Sci. Eng., 2006, 52, 305-316.

26 A. Jada, H. Ridaoui, L. Vidal and J. B. Donnet, Colloids Surf., A, 2014, 458, 187-194.

27 H. Ridaoui, A. Jada, L. Vidal and J. B. Donnet, Colloids Surf., A, 2006, 278, 149-159.

28 Z. Anfar, M. Zbair, H. A. Ahsaine, M. Ezahri and N. El Alem, Fullerenes, Nanotubes, Carbon Nanostruct., 2018, 26, 389-397.

29 H. A. Ahsaine, M. Zbair, Z. Anfar, Y. Naciri, R. El, N. El Alem and M. Ezahri, Mater. Today Chem., 2018, 8, 121-132.

30 A. Elouahli, M. Zbair, Z. Anfar, H. A. Ahsaine, H. Khallok, R. Chourak and Z. Hatim, Surf. Interfaces, 2018, 13, 139-147.

31 Z. Anfar, R. El Haouti, S. Lhanafi, M. Benafqir, Y. Azougarh and N. El Alem, J. Environ. Chem. Eng., 2017, 5, 5857-5867.

32 P. J. F. Harris, Z. Liu and K. Suenaga, J. Phys.: Condens. Matter, 2008, 20, 1-5.

33 M. E. Casco, M. Martínez-Escandell, K. Kaneko, J. Silvestre-Albero and F. Rodríguez-Reinoso, Carbon, 2015, 93, 11-21.

34 Y. Huang, F. S. Cannon, J. K. Watson, B. Reznik and J. P. Mathews, Carbon, 2015, 83, 1-14.

35 C. Bommier, R. Xu, W. Wang, X. Wang, D. Wen, J. Lu and X. Ji, Nano Energy, 2015, 13, 709-717.
36 J. Liu, N. Sun, C. Sun, H. Liu, C. Snape, K. Li, W. Wei and Y. Sun, Carbon, 2015, 94, 243-255.

37 B. Chang, D. Guan, Y. Tian, Z. Yang and X. Dong, J. Hazard. Mater., 2013, 262, 256-264.

38 B. Chang, H. Yin, X. Zhang, S. Zhang and B. Yang, Chem. Eng. J., 2017, 312, 191-203.

39 B. Chang, Y. Guo, Y. Li, H. Yin, S. Zhang, B. Yang and X. Dong, J. Mater. Chem. A, 2015, 3, 9565-9577.

40 Y. Haldorai, W. Voit and J.-J. Shim, Electrochim. Acta, 2014, 120, 65-72.

41 Z. Anfar, A. Amedlous, A. Ait El Fakir, H. Ait Ahsaine, M. Zbair, S. Lhanafi, R. El Haouti, A. Jada and N. El Alem, ACS Omega, 2019, 4, 9434-9445.

42 S. Vasudevan and J. Lakshmi, RSC Adv., 2012, 2, 5234-5242. 43 W. Song, B. Gao, X. Xu, F. Wang, N. Xue, S. Sun, W. Song and R. Jia, J. Hazard. Mater., 2016, 304, 280-290.

44 F. Tuinstra and J. L. Koenig, J. Chem. Phys., 1969, 31, 646650.

45 A. C. Ferrari and J. Robertson, Phys. Rev. B: Condens. Matter Mater. Phys., 2013, 10, 26-31.

46 A. Lazzarini, A. Piovano, R. Pellegrini, G. Agostini, S. Rudić, C. Lamberti and E. Groppo, Phys. Procedia, 2016, 85, 20-26.

47 B. Chang, S. Zhang, L. Sun, H. Yin and B. Yang, RSC Adv., 2016, 6, 71360-71369.

48 H. W. Kwak, Y. Hong, M. E. Lee and H. J. Jin, Int. J. Biol. Macromol., 2018, 120, 906-914.

49 G. K. Poongavanam and V. Ramalingam, Int. J. Therm. Sci., 2019, 136, 15-32.

50 L. Liang, M. Zhou, W. Yang and L. Jiang, Chem. Eng. J., 2018, 352, 673-681.

51 J. Sun, X. Liu, F. Zhang, J. Zhou, J. Wu, A. Alsaedi, T. Hayat and J. Li, Colloids Surf., A, 2019, 563, 22-30.

52 Z. Anfar, A. Amedlous, A. A. El Fakir, M. Zbair, H. Ait Ahsaine, A. Jada and N. El Alem, Chemosphere, 2019, 236, 124351.

53 Z. Anfar, H. Ait Ahsaine, M. Zbair, A. Amedlous, A. Ait El Fakir, A. Jada and N. El Alem, Crit. Rev. Environ. Sci. Technol., 2019, 1-42.

54 Z. Anfar, M. Zbair, H. A. Ahsaine, Y. Abdellaoui, A. A. El Fakir, E. H. Amaterz, A. Jada and N. El Alem, ChemistrySelect, 2019, 4, 4981-4994.

55 V. Rocher, A. Bee, J. M. Siaugue and V. Cabuil, J. Hazard. Mater., 2010, 178, 434-439.

56 M. Şaban Tanyildizi, Chem. Eng. J., 2011, 168, 1234-1240.

57 M. Laabd, H. Ait Ahsaine, A. El Jaouhari, B. Bakiz, M. Bazzaoui, M. Ezahri, A. Albourine and A. Benlhachemi, J. Environ. Chem. Eng., 2016, 4, 3096-3105.

58 H. A. Ahsaine, M. Zbair and R. El Haouti, Desalin. Water Treat., 2017, 85, 330-338.

59 I. Langmuir, J. Am. Chem. Soc., 1916, 38, 2221-2295.

60 H. Freundlich, Z. Phys. Chem., 1907, 57, 385-470.

61 A. Benhouria, M. A. Islam, H. Zaghouane-Boudiaf, M. Boutahala and B. H. Hameed, Chem. Eng. J., 2015, 270, 621-630.

62 K. W. Jung, B. H. Choi, M. J. Hwang, T. U. Jeong and K. H. Ahn, Bioresour. Technol., 2016, 219, 185-195. 